\title{
حكمة تعدّد الزوجات في الإسلام والطب
}

أ. سيدآقا سـائس، أ. عبدالخالق مصبباح، أ. اونيبا صيقل، أ.د.لطف الله آريابور، أ.د.صنيع الله زلهي،

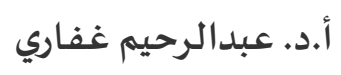

قسم الثقافة الإسلامية - و قسم علم وظائف الأعضاء و قسم علم التشريح- جامعة كابول للعلوم الطبية (ابوعلي ابن سينا) sayes1975@gmail.com

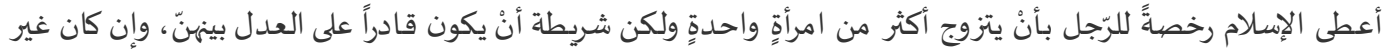

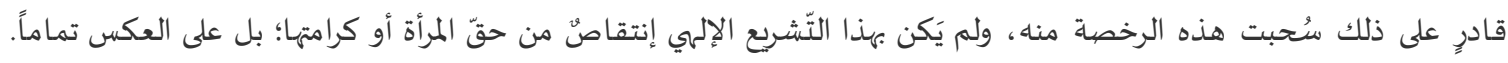

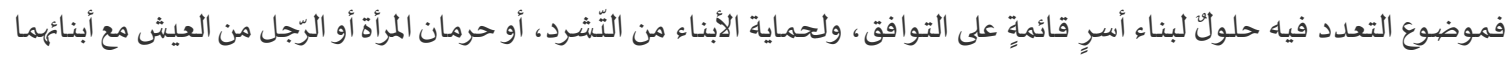

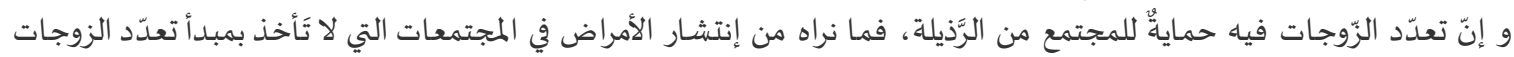

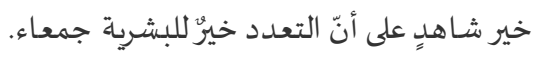

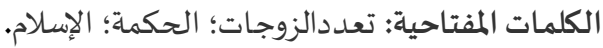

\section{(c) (1)}

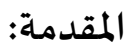

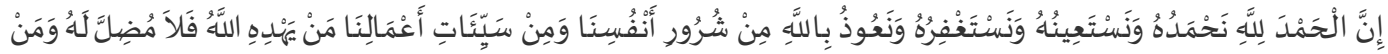

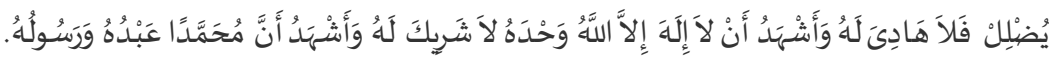

أما بعد:

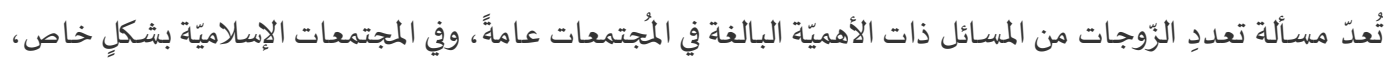

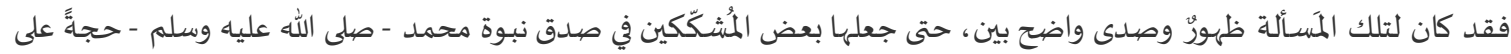

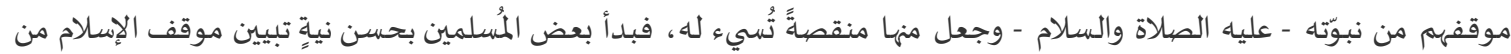

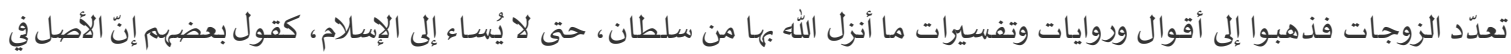

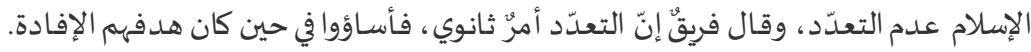

$$
\text { تأهمية موضيوع الهمية موضوع البحث في الأمور الآتية: }
$$

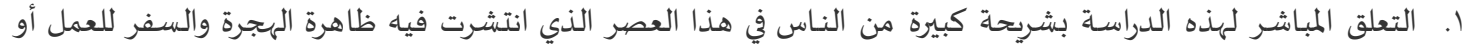

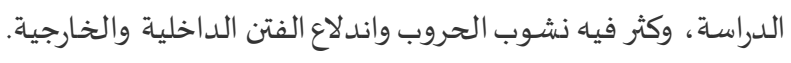

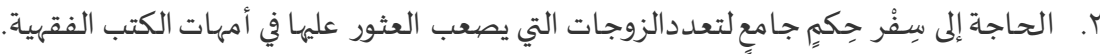

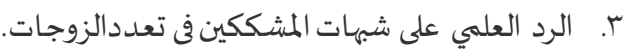

أهداف البحث:

من الأهداف التي سعى البحث لتحقيقها، نذكر ما يلي:

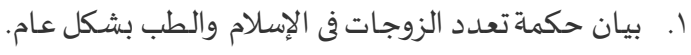

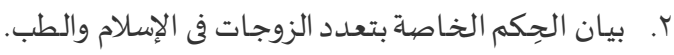

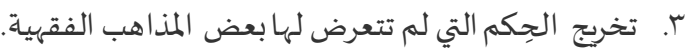


اعتمدنا في كتابة هذا البحث على المنهج الوصفي التَّحليلي، من خلال الإستقراء الجزئي للنصوص الشرعية وكلام الفقهاء

المتعلقة بالتشريع الأسري حول حكمة تعددالزوجات، وبطط المقدمات بنتائجها والوصول من الكليات إلى الجزئيات باستخدالإستدلال المباشروغيرالمباشر.

حدود البحث:

ليس من صيميم هذالبحث تناول جميع مايتعلق بِحِكم تعدد الزوجات فى الإسلام والطب وإنما اقتصرت حدوده على بيان أهم الِحكم التي يكثر النقاش حولها في وقتنا المعاصر.

مشكلة البحتث:

الرجل بطبيعته يحب التعدد، وهناك العديد منهم الذين لا يكفيهم إمرأة واحدة في حياتهم، لذلك تجده هم يمارسون بعض العلاقات الغير شرعية مع نساء أخريات وهذا في حد ذاته يؤدي إلى إنتشار الأمراض نتيجة هذه العلاقات المحرمة التي تسبب الإصابة

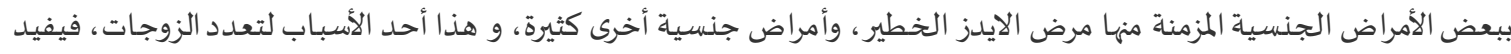

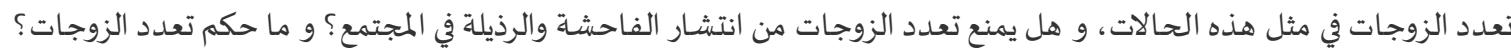

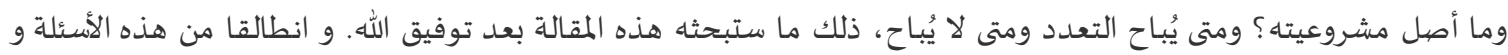

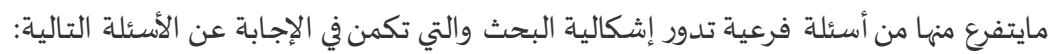

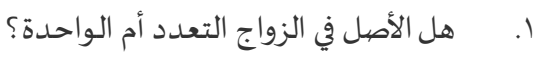

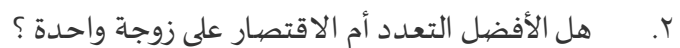

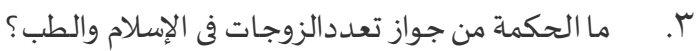

الدراسـات السـابقة:

لا تزعم هذه الدراسة الأسبقية المطلقة في هذا المجال بشكل عام، وأها الأولى دون منازع، فقد بحث الفقهاء الأجلاء هذه

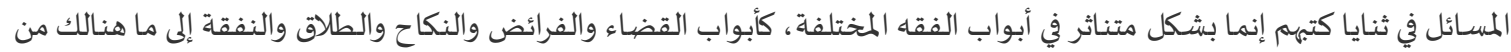

وثمة دراسـات وكتابات حديثة تناولت مسائل من هذه الدراسة، غير أن هذا البحث يتميز عما سبقه من دراسات، أنه جمع

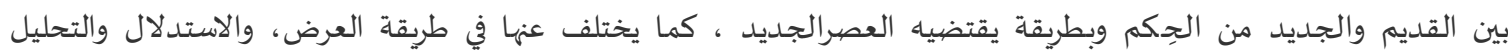

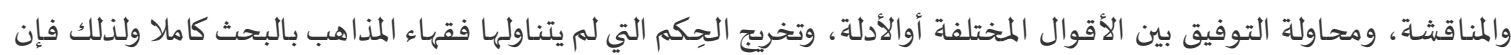

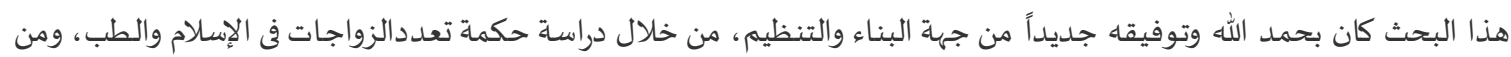
جهة الموضوع، من خلال طريقة العرض واستقصياء الأدلة والمناقشة وتخريج الأحكام.

خطة البحث:

يشتمل هذالبحث على مقدمة و مبحثين وقد جاءت الخطة على النحو الآتي:

المقدمة :وتقدمت بما اشتلت عليه.

• المبحث الأول : مفهوم الحكمة: لغنةً وشرعًا.

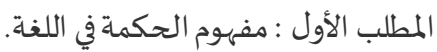

المطلب الثاني : مفهوم الحكمة و معنى تعدد الزوجات في الإصطلاح الشرعي.

المطلب الثالث : حكم تعدد الزوجات في الشرائع السماوية.

المطلب الرابع: المناقشة و فيها تحرير محل النزاع في المسألة وذكر الآراء ثم النقاش والترجيح الفقهي المستند إلى الدليل. • المبحث الثاني : حكمة تعددالزوجات في الإسلام والطب.

المطلب الأول:الحِكم الدينية والأخلاقية. 
المطلب الثاني:الحِكم الصحية والنفسية.

الخاتمة: و فهها أهم النتائج المتوصيّل إليها والتوصيات.

\section{المبحث الأول: مفهوم الحكمة: لغنةً وشرعًا}

المطلب الأول: مفهوم الحكمة في اللغة:

جاءت كلمة الحكمة في اللغة بعدة معان، منها: 1. تستعمل بمعنى: العدل، والعلم، والحلم، والنبوة، والقرآن، والإنجيل.

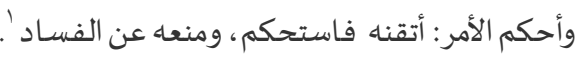

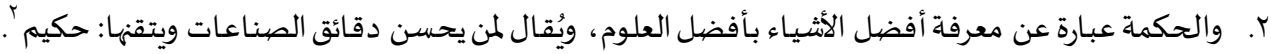

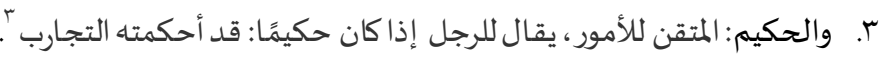

ع. والحَكَمُ والحكيم هما بمعنى: الحاكم والقاضي، والحكيم فعيل بمعنى فاعل، أو هو الذي يُحكِمُ الأشياء ويتقنهاء.

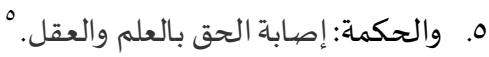

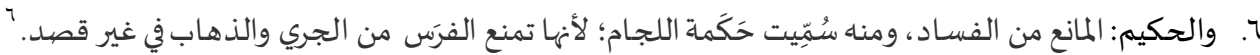

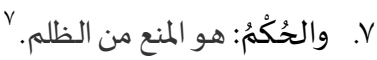

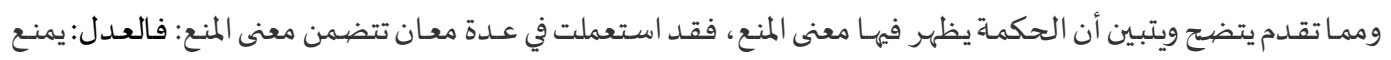

صاحبه من الوقوع في الظلم والحلم: يمنع صاحبه من الوقوع في الغضب والعلم: يمنع صاحبه من الوقوع في الجهل.

المطلب الثاني: مفهوم الحكمة و تعدد الزوجات في الاصطلاح الشرعي

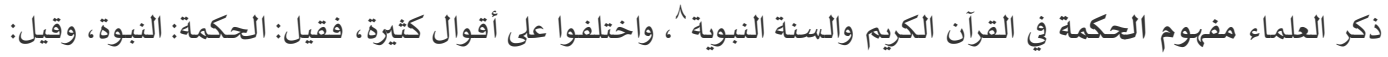

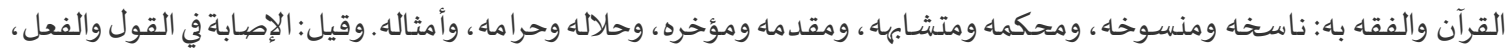

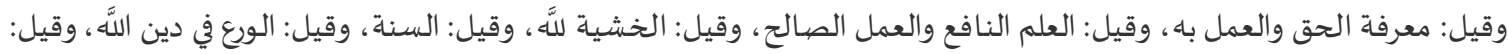

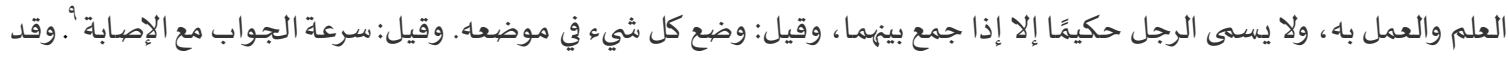

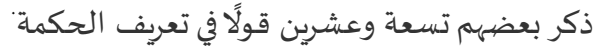
وهذه الأقوال كلها قريب بعضها من بعض؛ لأن الحكمة مصدر من الإحكام، وهو الإتقان في قـول أو فعل، فكل ما ذكر فهو

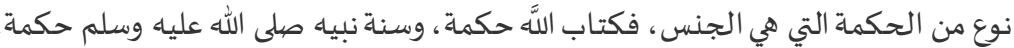

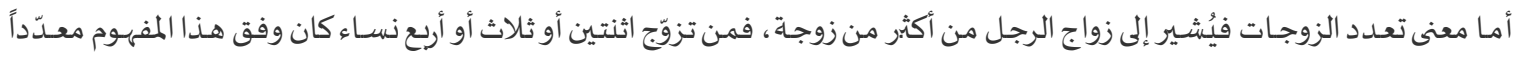

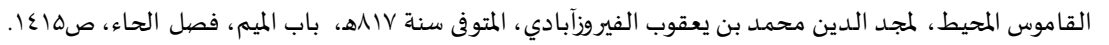

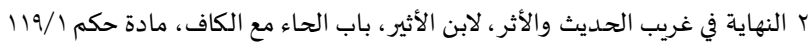

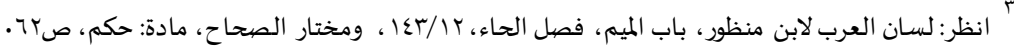

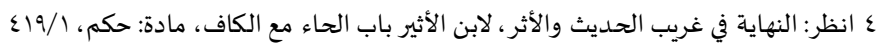

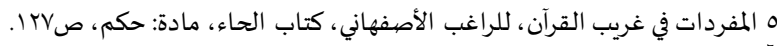

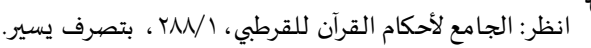

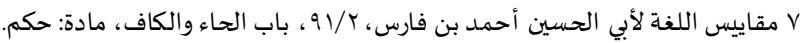

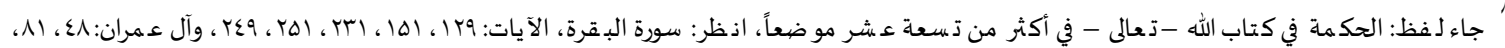

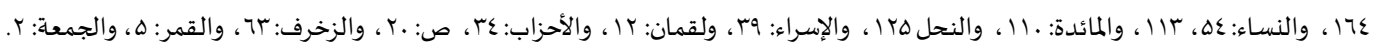

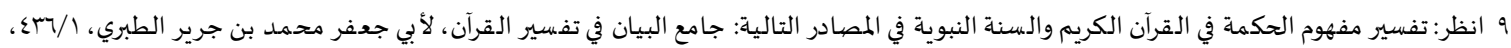

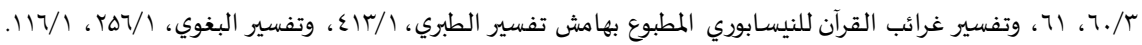


للزّوجات، ويكون الزواج من المرأة الثانية، أو الثالثة، أو الرابعة وفق الشروط والأحكام نفسها التي تكون في عقد الزواج ' .

$$
\text { المطلب الثالث : حكم تعدد الزوجات في الشر ائع السماوية }
$$

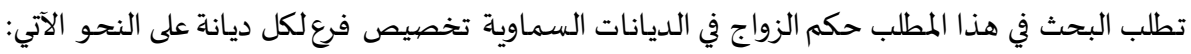

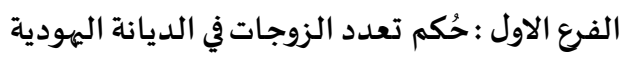

وتعدد الزوجات جائز في الشريعة الههودية ولا يجد نص واحد يحرمه لا في الكتاب المقدس ولا في التلمود وكان العرف جاري

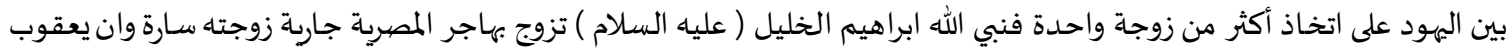

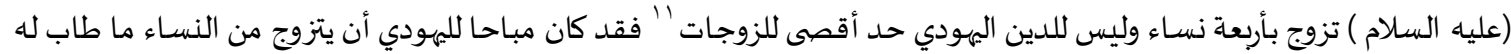

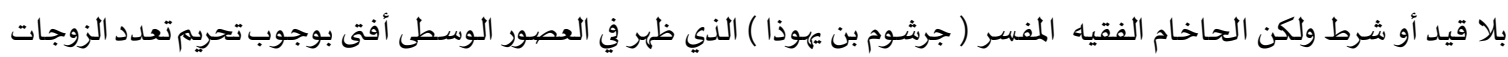

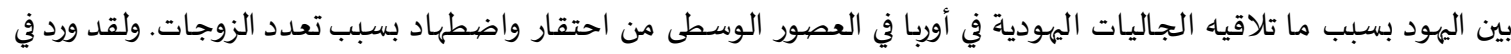

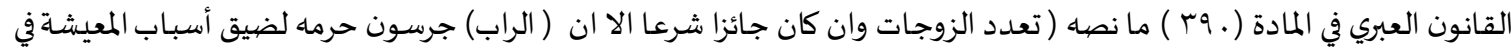

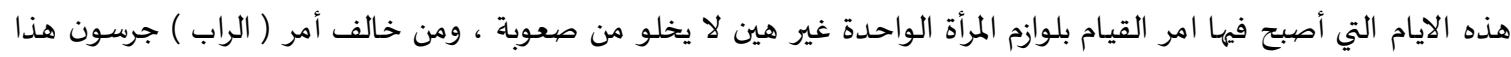

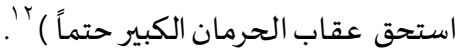

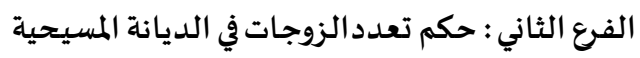
إن تعدد الزوجات كان معمولا باه في مطلع المسيحية تبعا للتعدد الذي كانت تعمل باه الههودية، وفي العصهور المتأخرة أصبح

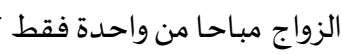

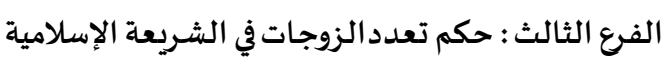

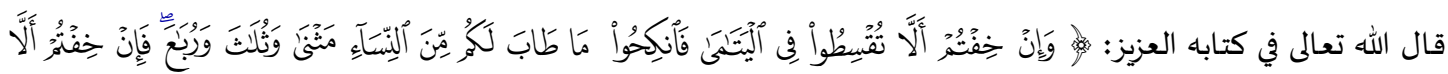

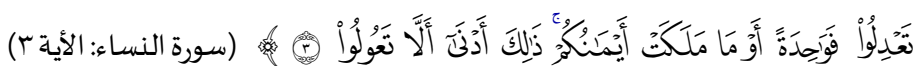

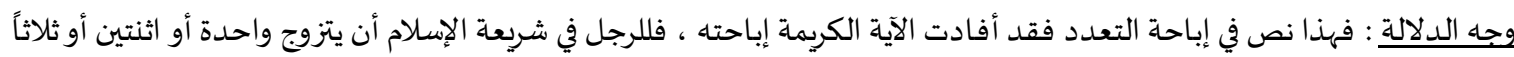

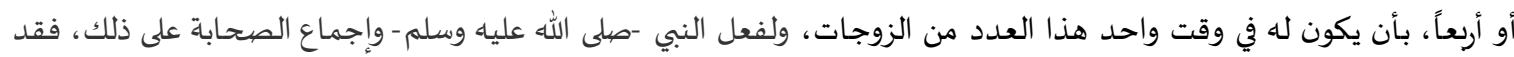

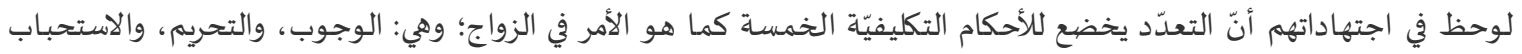

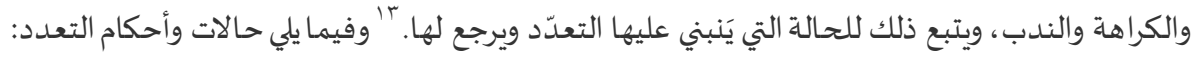

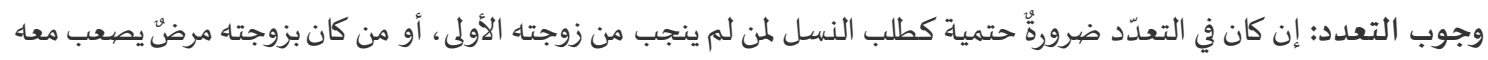

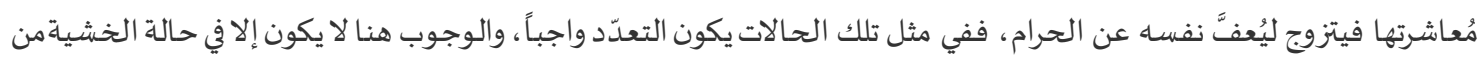

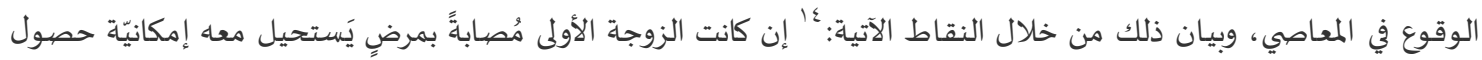

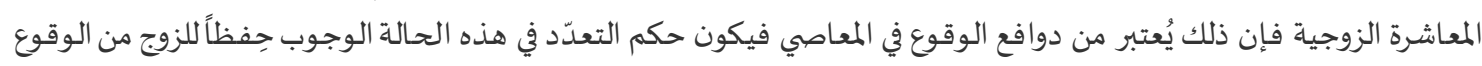

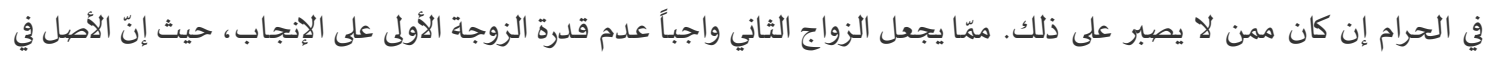

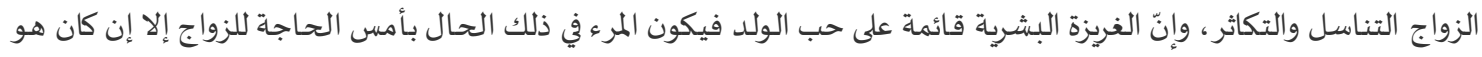

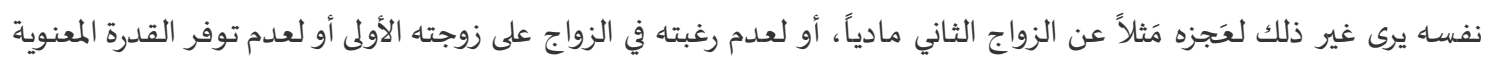

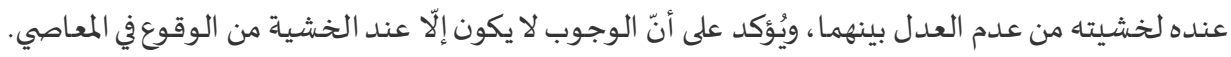

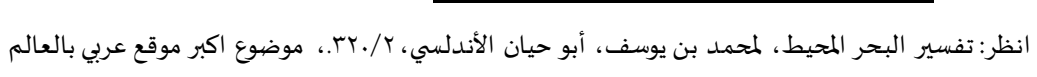
https://webcache.googleusercontent.com/=

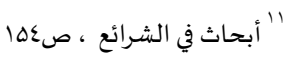

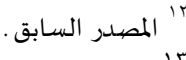

الإمام الشافعي أبو عبد الله محمد بن إدريس بن العباف المباس بن عثمان بن شافع بن عبد المطلب بن عبد مناف المطلبي القرشي (.199)، الأم، بيروت: دار

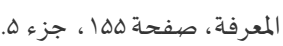

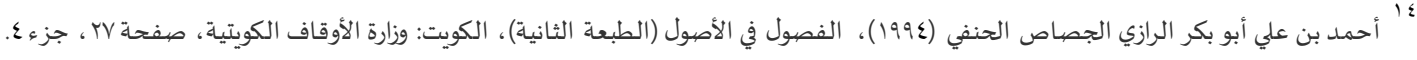




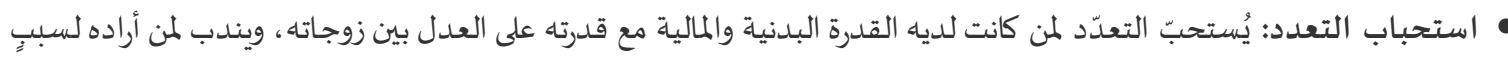

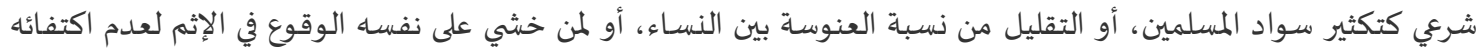

• كراهية التعدد: يُكره التعدد لمن كانت لديه القدرة المالية والجسـديّة، ولكن غلب عليه الظن بعدم القدرة على العدل بين الزوجات.

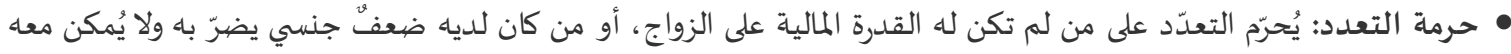

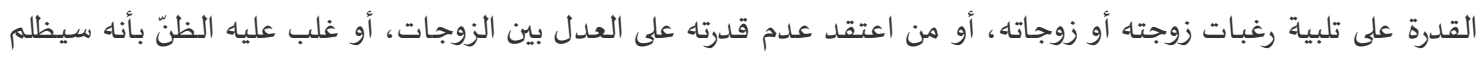

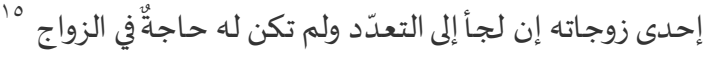

المطلب الرابع: المناقشة

لاخلاف بين المسلمين بأن تعدد الزوجات حلال ومشروع و هو بالتأكيد من الحلال الممكن شرط العالعدالة والمالة والمقدرة ، لكنها

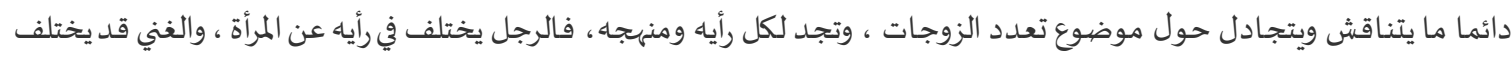

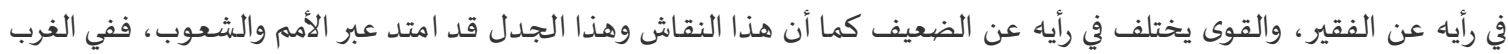

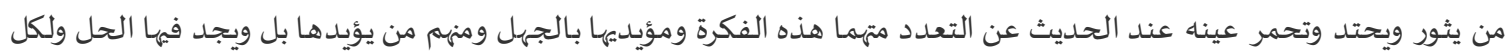

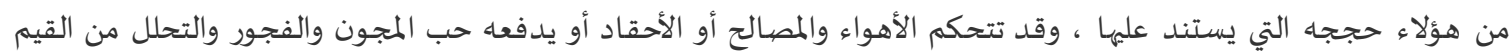

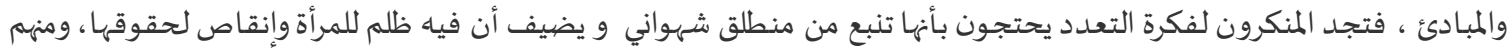

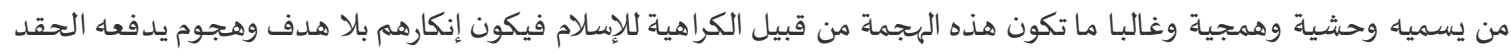

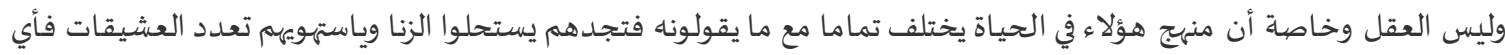

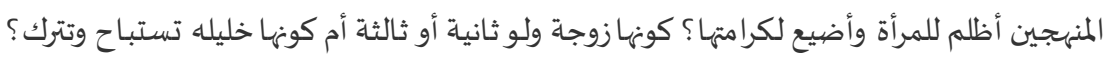

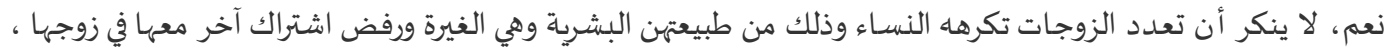

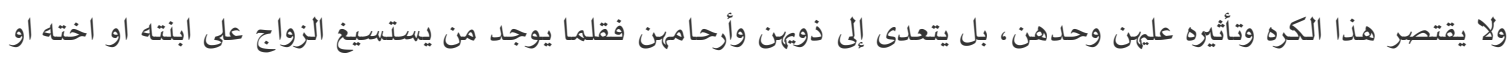

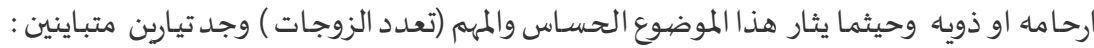

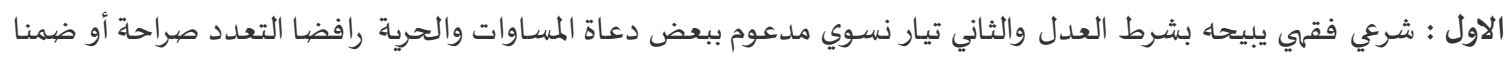

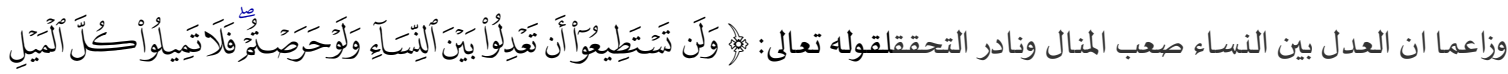

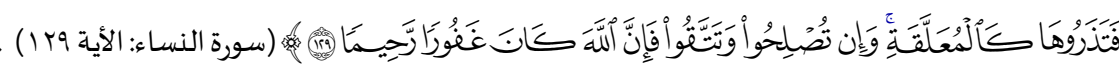

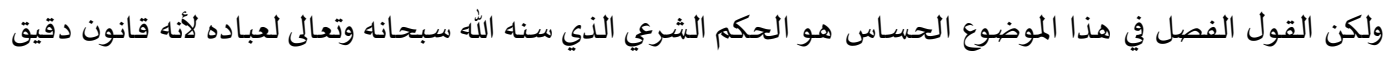

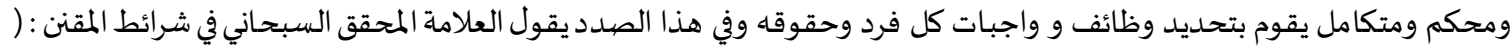

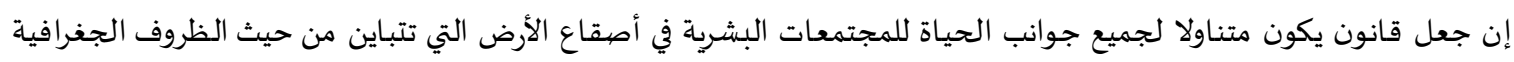

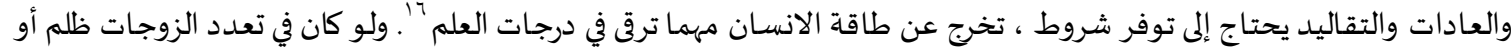

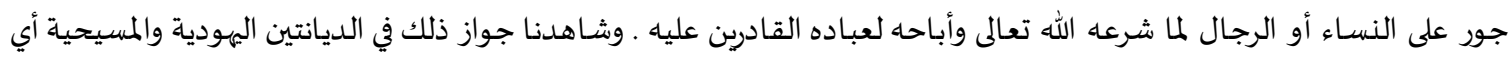

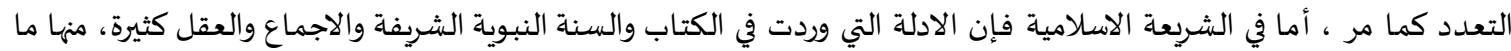

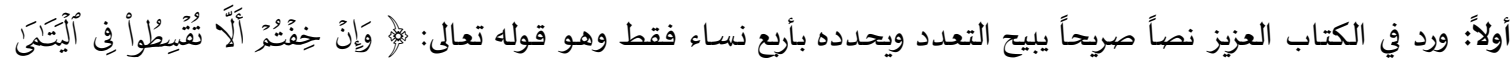

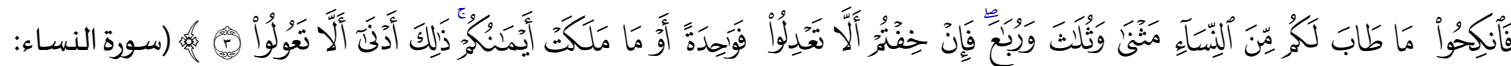

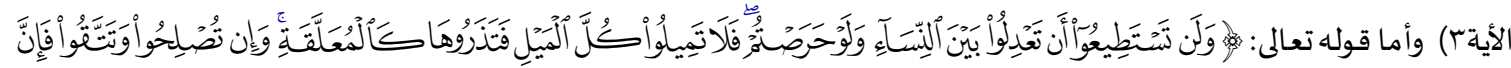

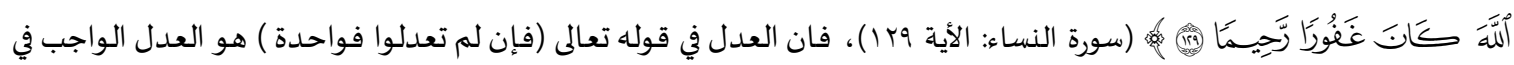

10 الإمام الشافعي أبو عبد الله محمد بن إدريس بن العباس بن عثمان بن شافع بن عبد المطلب بن عبد مناف المطلبي القرشي (ـ199)، الأم، بيروت: دار

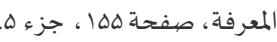

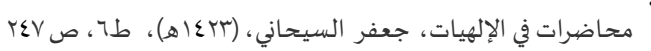


القسم بين النساء من طعام وكسوة ومنزل ومبيت, والعدل في قوله تعالى (ولن تستطيح أن تعدلوا ) هو العدل في الحب والميل القلبي

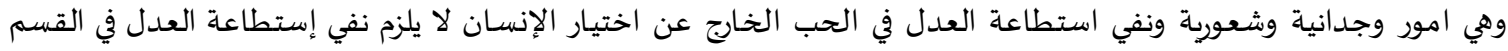

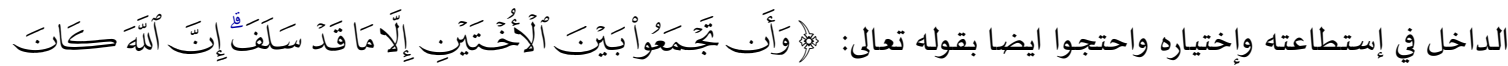

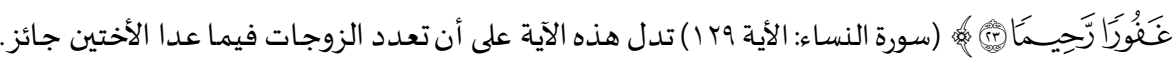

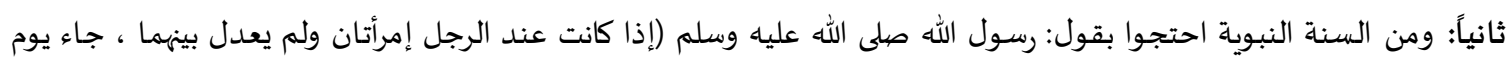

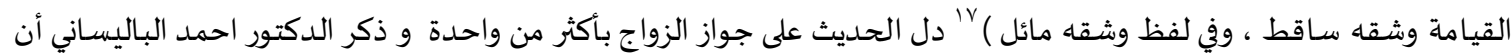

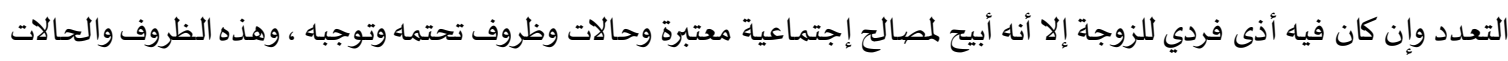

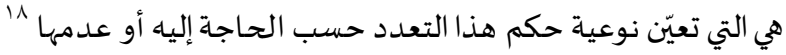

$$
\begin{aligned}
& \text { المبحث الثاني : حكمة تعددالزوجات فى الإسلام والطب } \\
& \text { المطلب الأول:الحِكم الدينية والأخلاقية }
\end{aligned}
$$

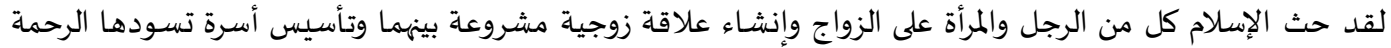

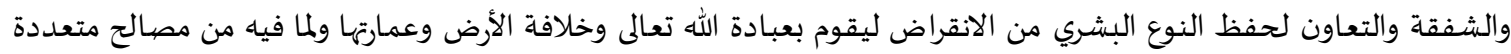

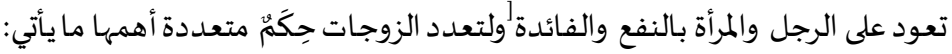

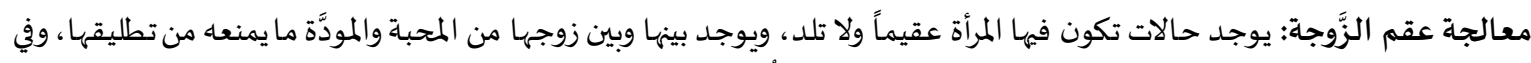

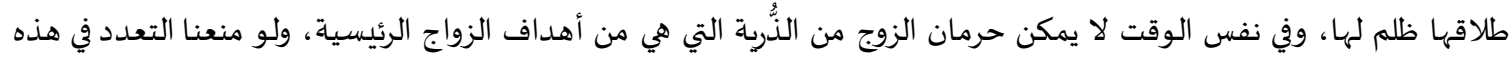

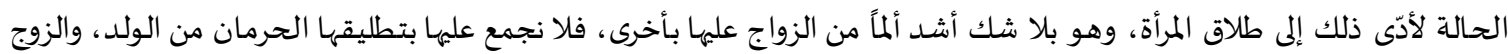
الذي يصونها ويكرمها.

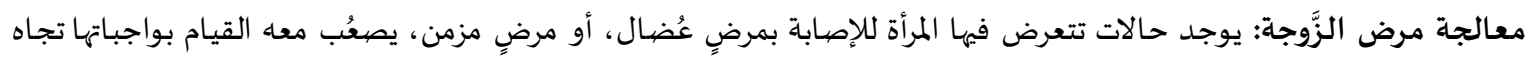

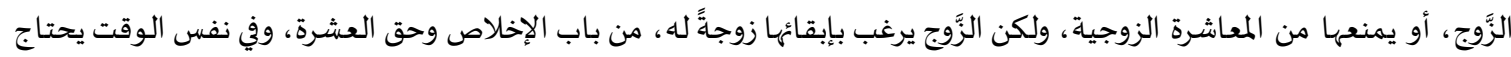

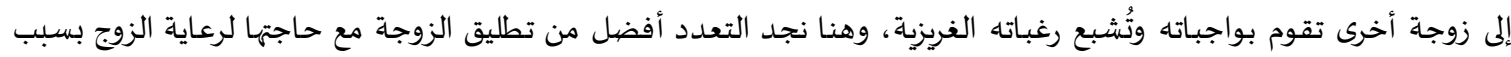

مرضها.

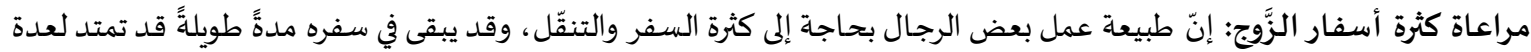

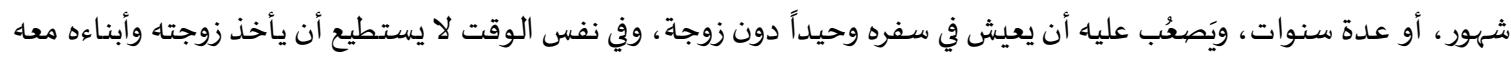

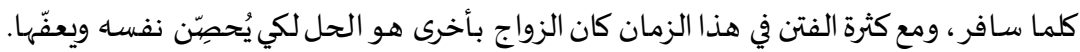

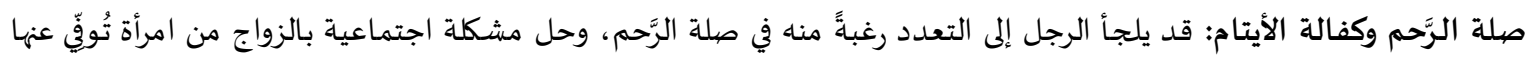

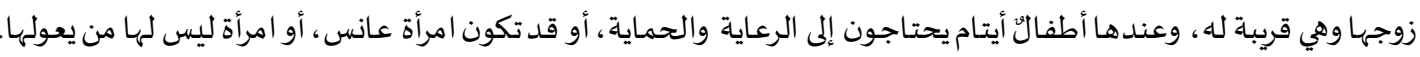

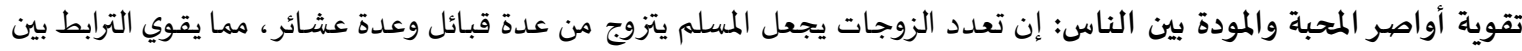

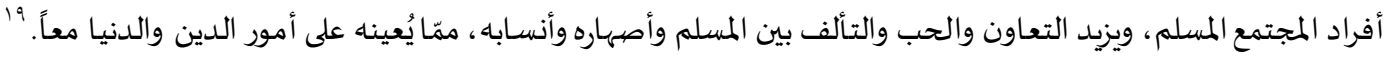

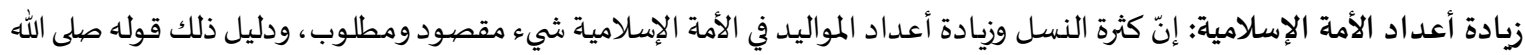

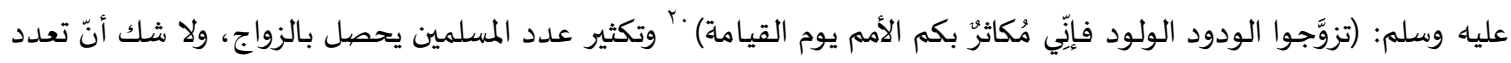
الزوجات سيؤدي إلى كثرة النسل، وهذا سيؤدي بدوره إلى زيادة عدد السكان، ويزيد القوى العاملة، ويحسّن الاقتصاد، وبالتاليالي يقوّي

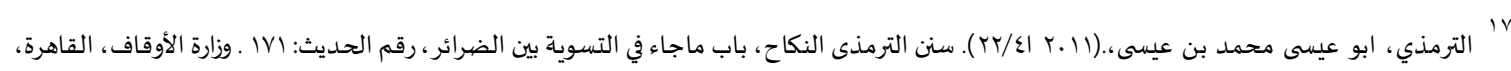

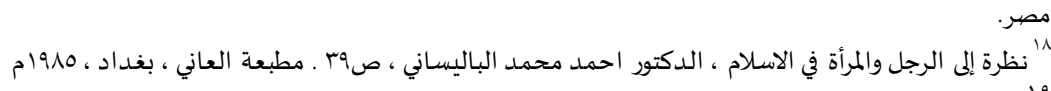

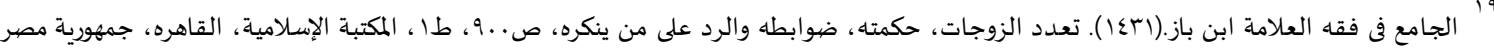

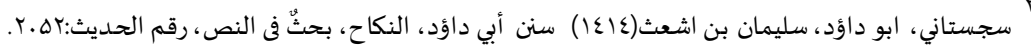


الأمة الإسلامية، خاصة عند استثمار موارد الدولة بالشكل المطلوب من قبل أشخاص مؤهّلين لذلك، لاسيّما أنّ الله تعالى - تكفّل برزق العباد.

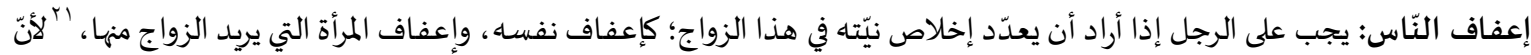

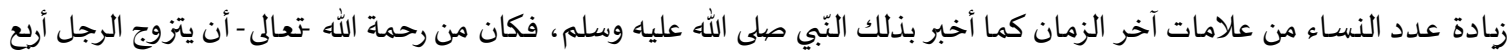

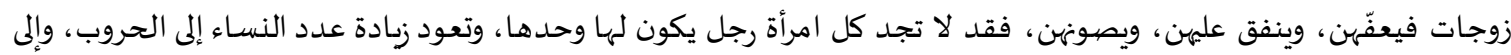

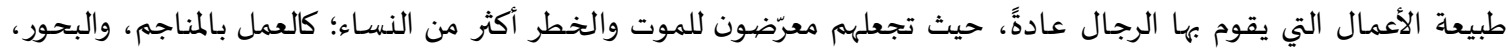

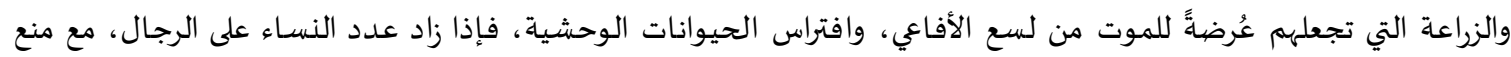

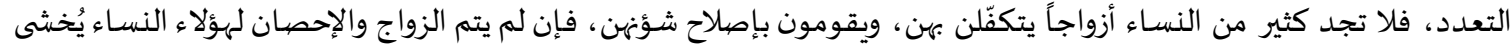
علهين من كثرة الفساد.

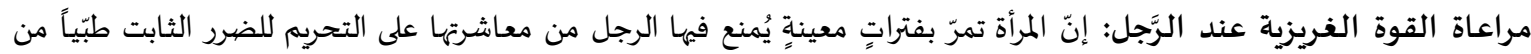

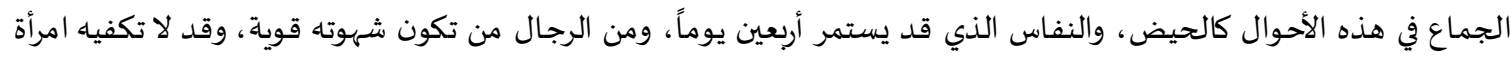

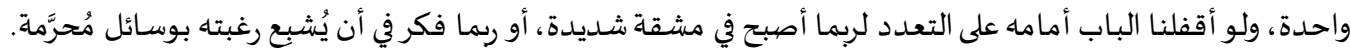

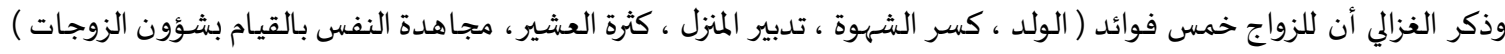

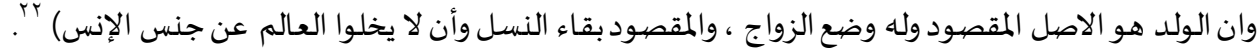

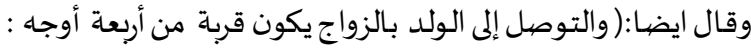

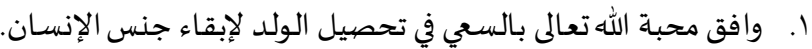

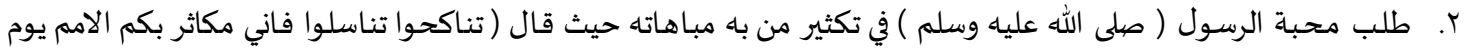

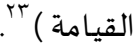

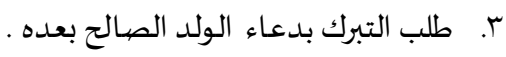
ع. طلب الشفاعة بموت الولد الصغير إذا مات قبله.

وهذه الفوائد الخمس والقربات الأربع لا تشمل الرجال فقط وإنما تشمل النساء ايضا، أما إذا حرمن من الزواج بسبب منع التعدد فإنهن يحرمن فضل هذه الآثار. المطلب الثاني:الحِكم الصحية والنفسية

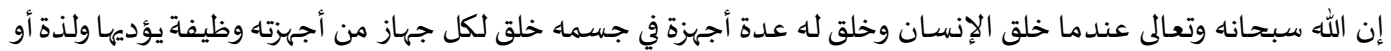

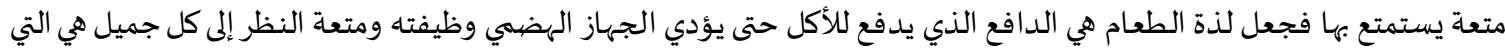

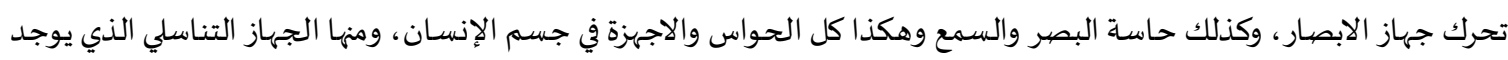

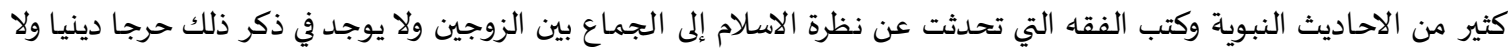

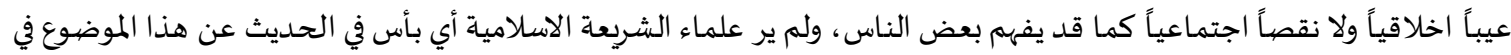
اطار العلم والتعليم ، فلاحياء في الدين أي تعلمها وتعليمهاه .

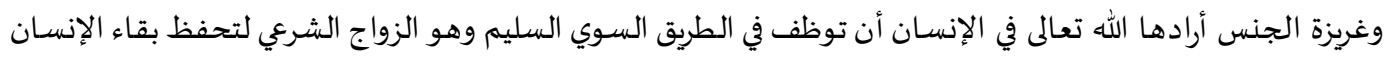
وامتداد سلالته في الإرض ولتتؤمن الإستقرار النفسي والإستمتاع بهذه النعمة، و لتجعل الجنسين حريصين على إنشاء الأسرة التي هي الإنيان الإنسان نواة المجتمع ويندفعان لتربية الأولاد وحمايتهم من المخاطر والشرور و كما يروح عن نفسه وفيه سكن للزوجين قال تعالى: وَوَمنْ

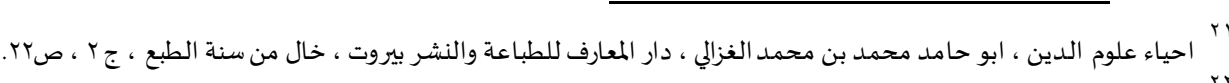

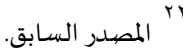

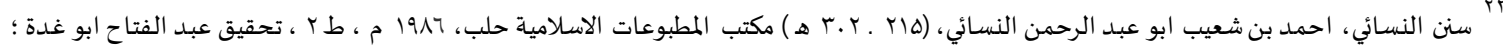




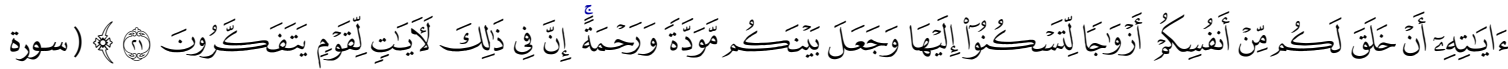

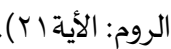

فهذه آية من آيات الفطرة الإلهية، وهي أقوى ما تعتمد عليه المرأة في ترك أبويها وأخوتها وسائر أهلها وترضى بالإتصال

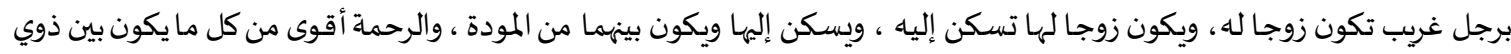

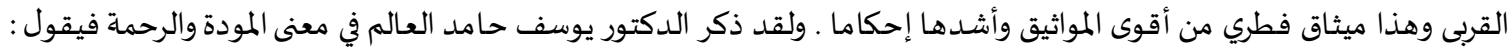

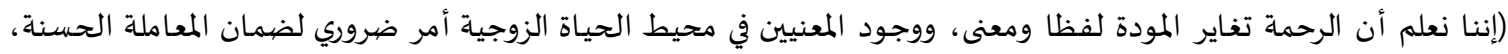

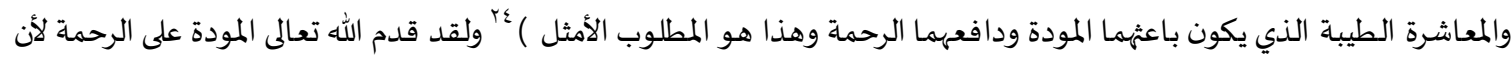

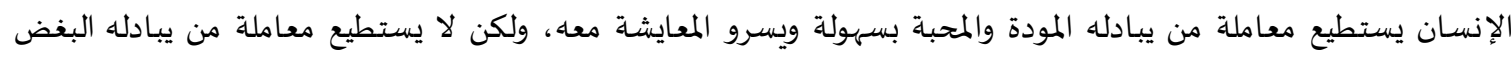

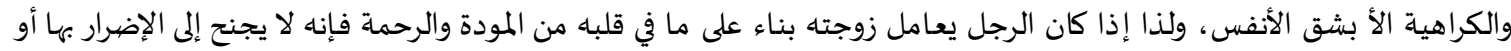

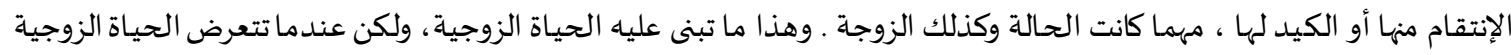

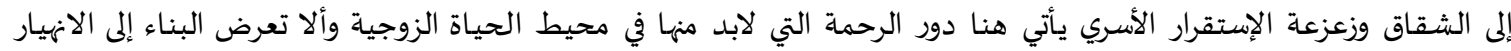

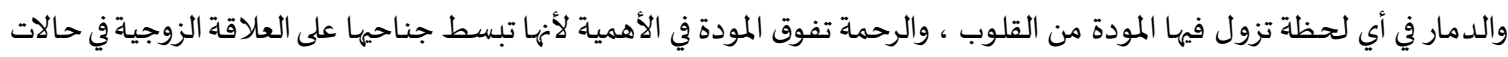

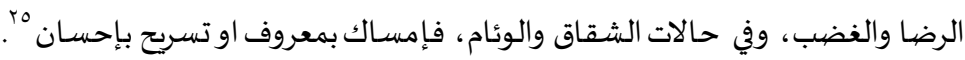

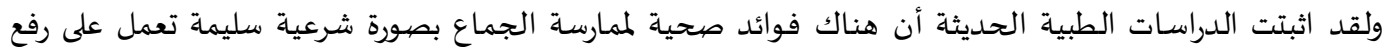

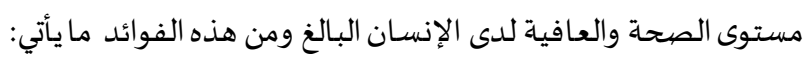

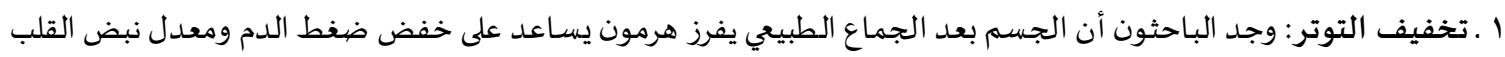

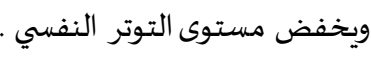

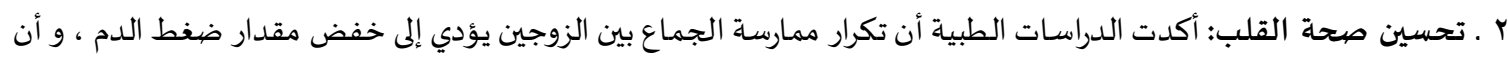

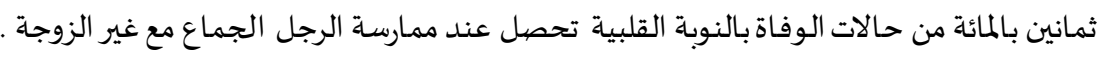

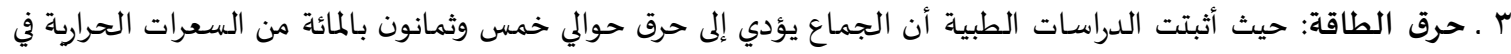

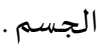
ع ـ احترام الذات: أشار الباحثون في السلوك الجنسي إن أحد أسباب قيام الإنسان بالجماع هو بحثه عما يرفع من شعوره باحترام

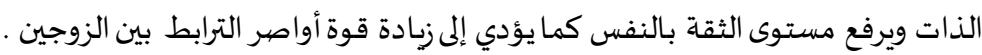

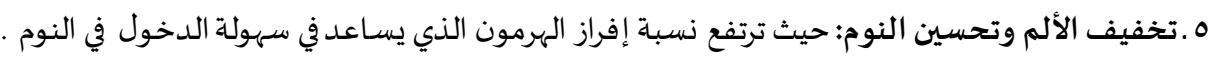
7 ـ ـ تنشيط مناعة الجسم: لاحظت الدراسات العلمية أن ممارسة الجماع تؤدي إلى رفع مستوى الاجسام المضادة وهي التي تحمي

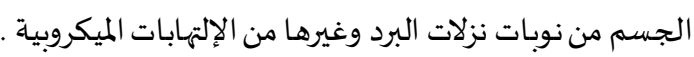

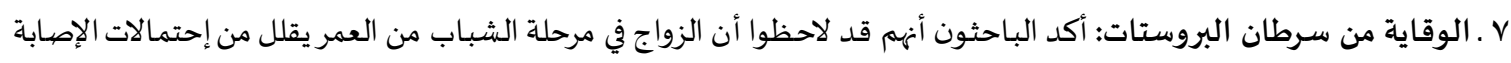

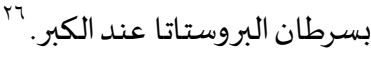

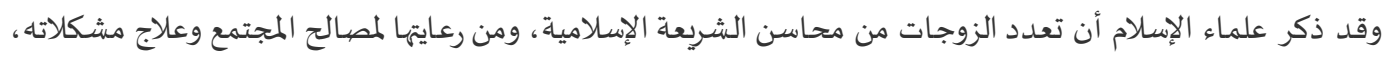

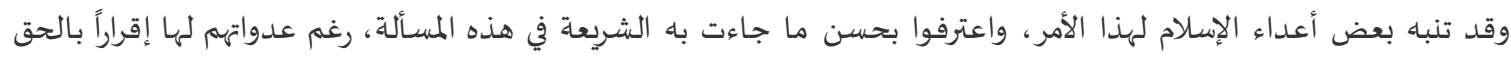

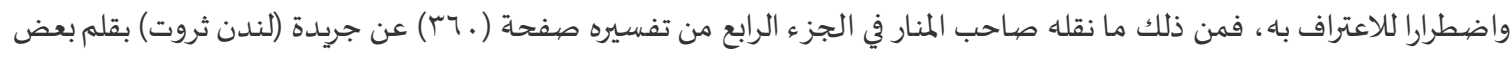

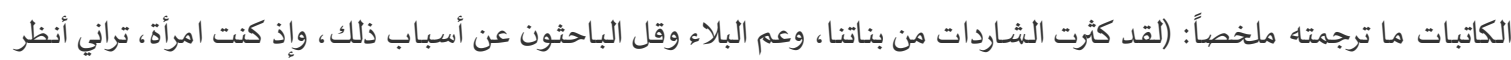

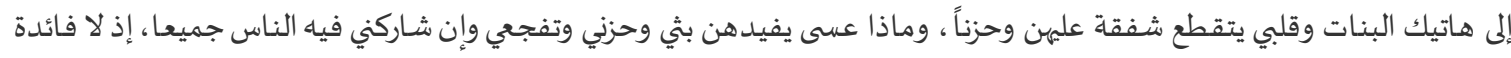

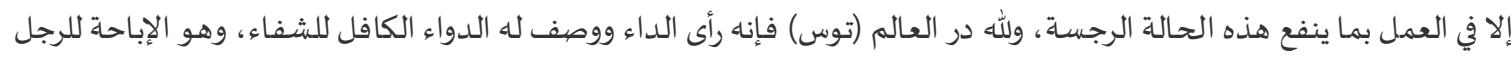

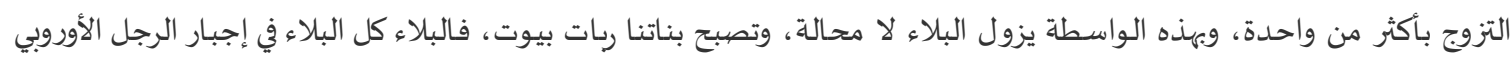

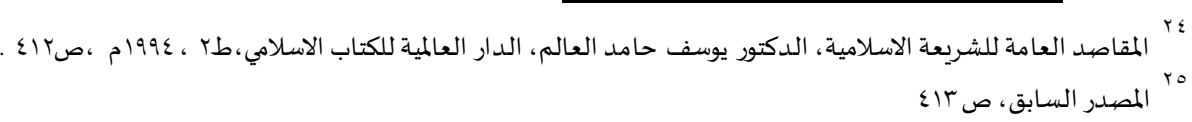

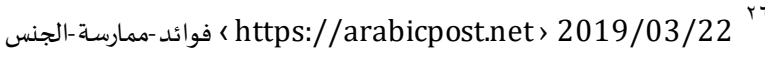


على الاكتفاء بإمرأة واحدة، فهذا التحديد هو الذي جعل بناتنا شوارد، وقذف بهن إلى إلتماس أعمال الرجل، ولا بد من تفاقم الشر

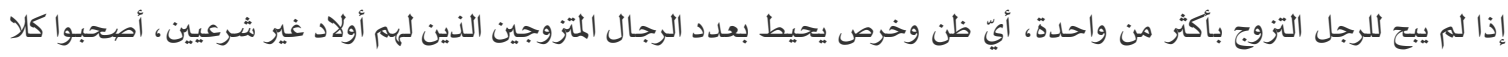

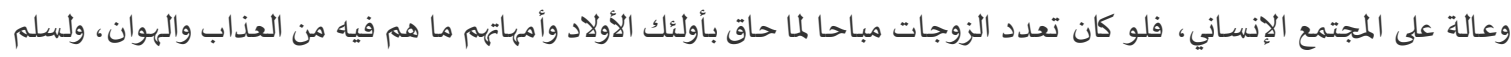

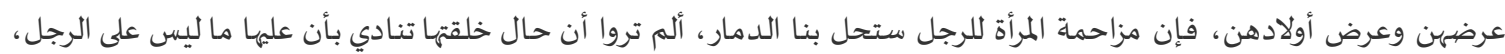

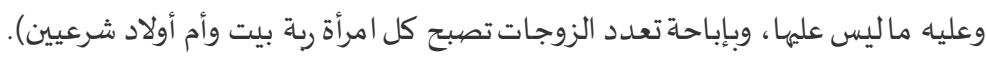

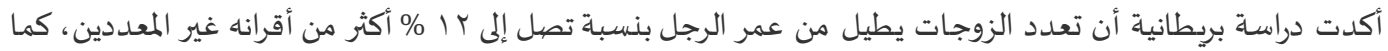
يؤدي إلى سعادته، وتحسّن أحواله المهنية والمادية.

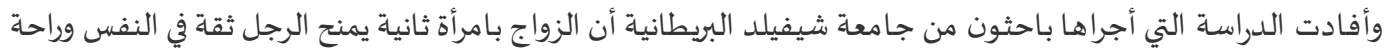

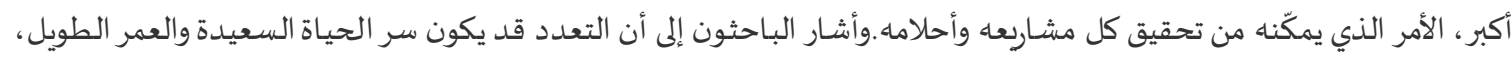

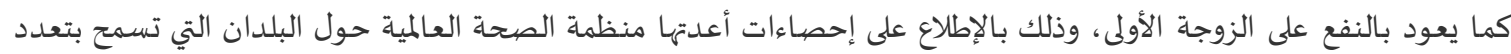

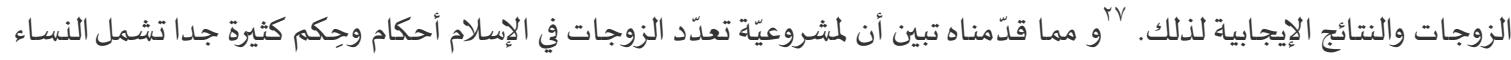

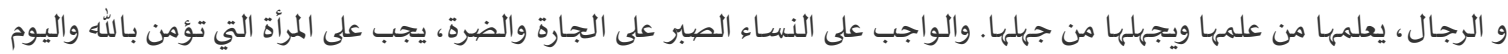

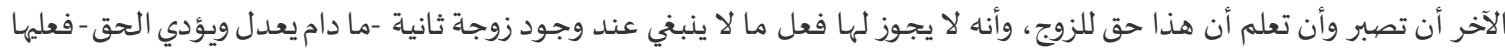

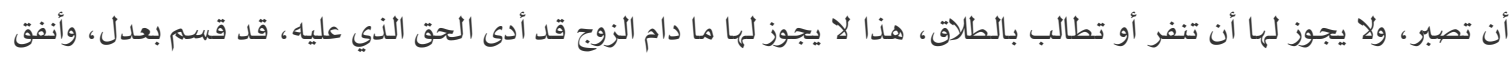

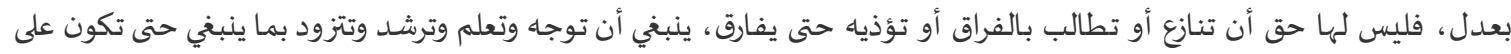

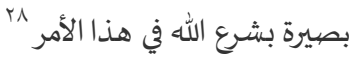

الخاتمة:

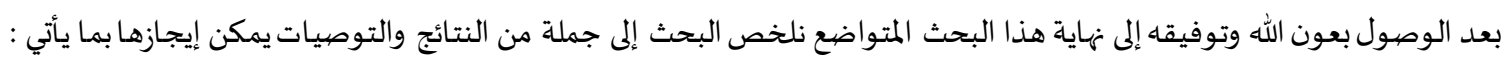

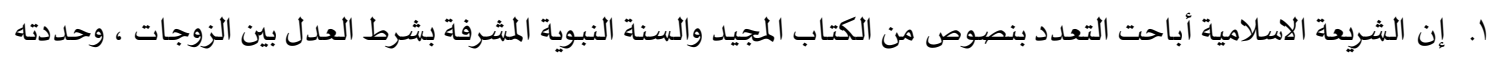

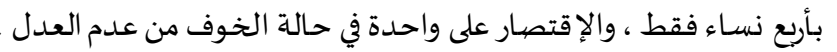

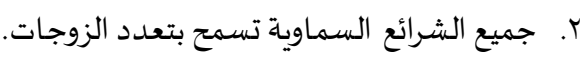

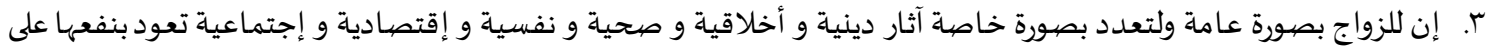

$$
\text { الفرد والمجتمع. }
$$

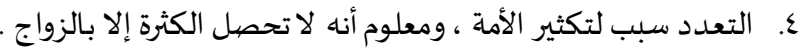

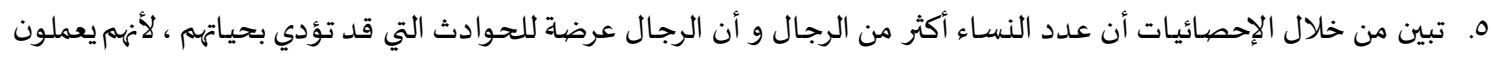

$$
\text { في المهن الشاقة. }
$$

צ. من الرجال من يكون قوي الشهوة، ولا تكفيه إمرأة واحدة و كذالك قد تكون الزوجة عقيمة أو لا تفي بحاجة الزوج، لذا فإن

أفضل حل هو الزواج الثاني.

المقترحات:

على أولياء الأمور من مسؤولين حكوميين ورجال دين و المجتمع كل من موقعه أن يساهموا في نشر الوعي والثقافة

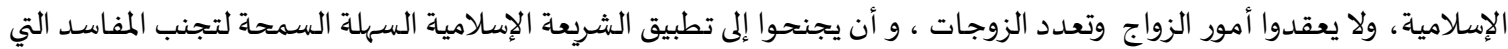

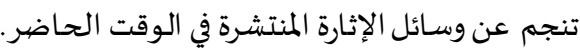


المرانع: الكربع:

القرآن الكريم برواية حفص عن عاصهم.

أولاً:الكتب:

ا. إبن أثير، مجد الدين أبو السعادات المبارك بن محمد ابن عبد الكريم الشيباني الجزري(ت: 7 ـ 7هـ) الههاية في غريب الحديث

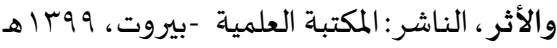

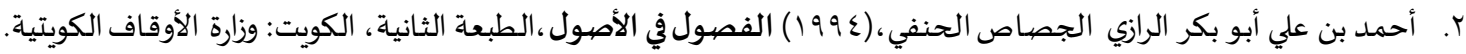

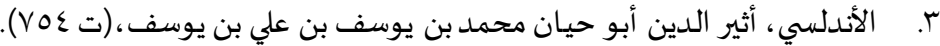

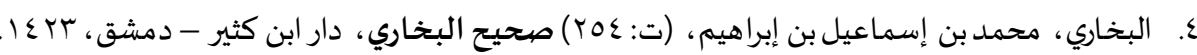

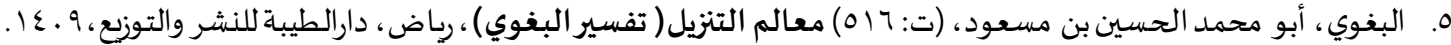

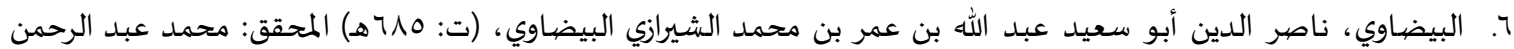

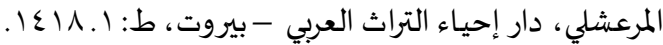

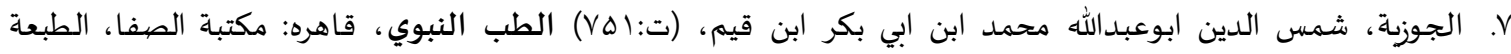

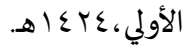

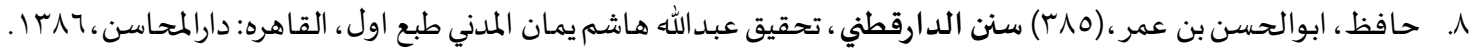

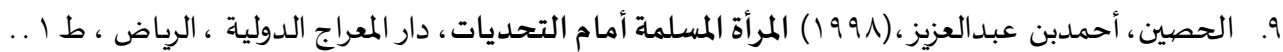

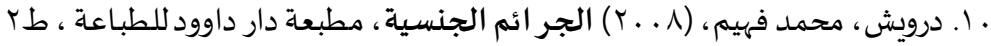

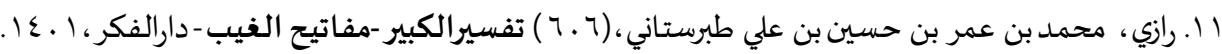

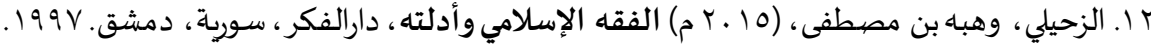

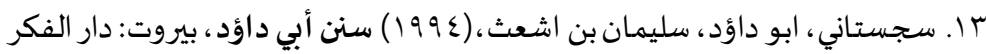

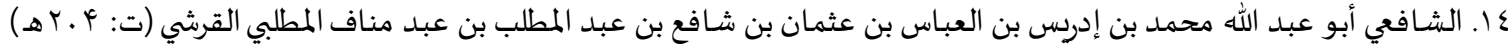
الأم، بيروت: دار المعرفة، . . 199. 199

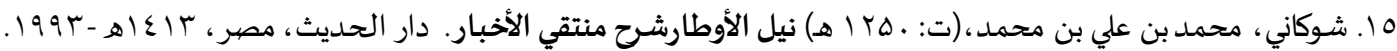

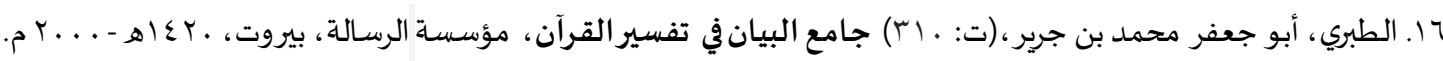

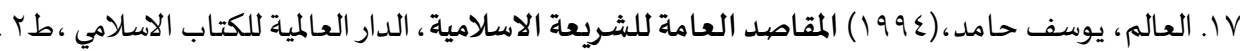

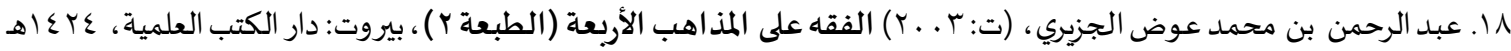
م. r. r.

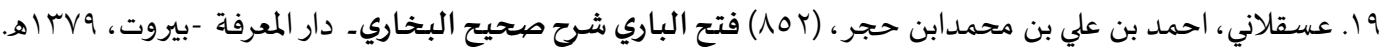

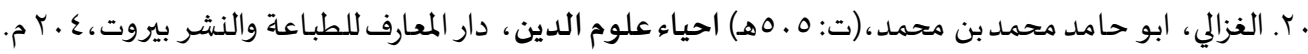

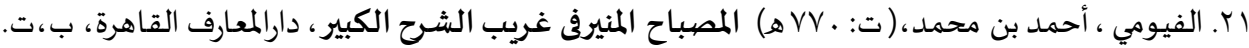

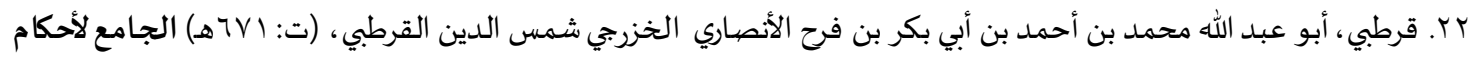

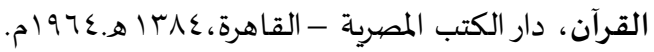

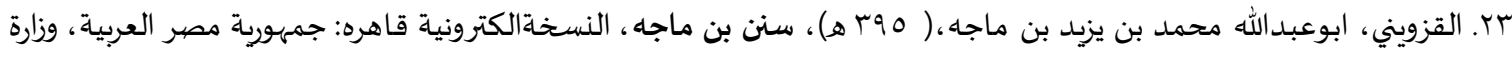

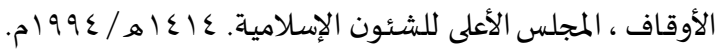

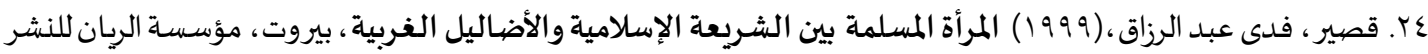
والتوزبع. ه إبن كثير، ابولفداء عمادالدين اسماعيل بن عمر، (ت VVV) تفسيرالقرآن العظيم، ط: ال، الفاروق الحديثية للطباعة والنشر،

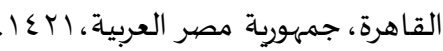

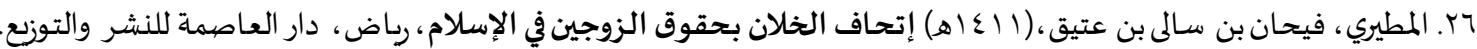

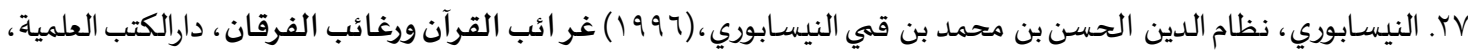
بيروت ، لبنان. 


$$
\begin{aligned}
& \text { ثانياً : كتب اللغة والمعاجم: } \\
& \text { 1. آبادي، الفيروز، (191V) القاموس المحيط، مؤسسة الرسالة، بيروت، ط .الثانية. }
\end{aligned}
$$

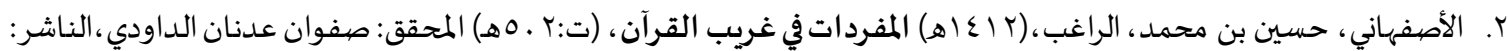

$$
\begin{aligned}
& \text { دار القلم، الدار الشامية - دمشق بيروت الطبعة: الأولى . }
\end{aligned}
$$

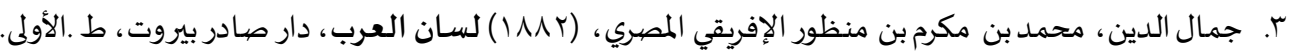

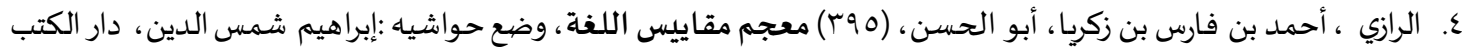

$$
\begin{aligned}
& \text { العلمية بيروت، ط .الأولى، } 1999 \text { م. م. } \\
& \text { ه. الرازي ، محمد بن أبي بكر بن عبد القادر الحنفي، زين الدين أبو عبد الله ، (777هـ ) مختار الصححاح، عنيت بضبطه وتصحيحها }
\end{aligned}
$$

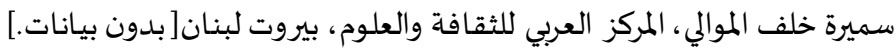

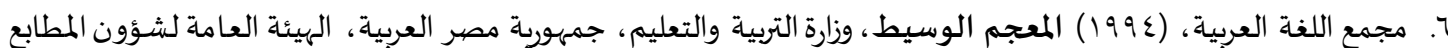

$$
\begin{aligned}
& \text { الأميرية القاهرة. } \\
& \text { ثالثاً: المو اقع الإلكترونية: }
\end{aligned}
$$

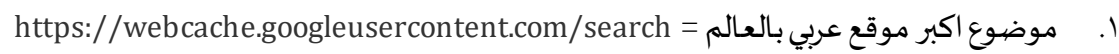

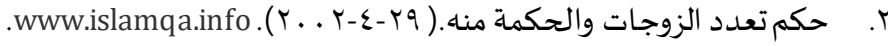

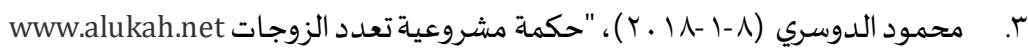

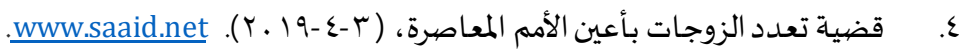

$$
\begin{aligned}
& \text { NewScietist. } 7 \text { Oct 2019 05:41:51 GMT .0 } \\
& \text { https://binbaz.org.sa/fatwas/2480 .T }
\end{aligned}
$$




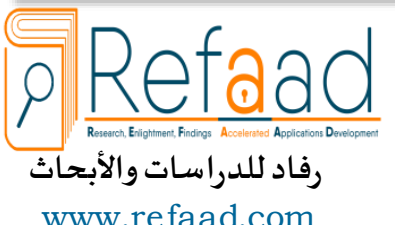

www.refaad.com
المجلة الدولية للدراسـات الإسلامية المتخصصية

e-ISSN 2617-6246 , p-ISSN 2617-6238

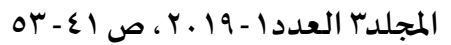

https://doi.org/DOI:10.31559/sis2019.3.1.3

\title{
The Rule of Polygamy in Islam and Medicine
}

\author{
Prof. Sayed Aqa says, Prof. Ab.khaliq Mesbah, Prof. Oniba Saiqal, prof. Dr. Lutfullah Ariapoor, \\ Prof Dr Ab.Rahim Ghafari \& Prof.Dr Saniullah Zalmai \\ Departments of Islamic Culture, Physiology and Anatomy, Kabul University of Medical \\ Sciences \\ sayes1975@gmail.com
}

Received Date: $28 / 10 / 2019$

Accepted Date: 2/12/2019

Abstract. Islam allows polygamy and permits men, under specific circumstances, to have at most four wives at any given time. But provided that; he was able to be fair to them, and if he was unable to do so, he cannot use this permission. This Islamic rules don't detract woman's rights but in contrast; Polygamy is a protection of families and children from dissociation and prevents parents from separation from their children. In addition, polygamy prevents society from lewdness and rascality that besides other troubles may spread diseases that is seen in societies where principle of polygamy is not allowed.

Keywords : polygamy; Hekmat (Wisdom); Islam

\section{References:}

[1] Ạl ạ̣lm. Ywsf Ḥạmd, Ạlmqạșd Ạl'ạmh Llsȟry'h Ạlạslạmyh, Ạldạr Ạl'cạlmyh Llktạb Ạlạslạmy ,Ṭ2, (1994)

[2] 'bd Ạlrḥmn Bn Mḥmd 'wḍ Ạljzyry, (T: 2003), Ạlfqh la Ạlmdhạhb Ạlạ̉rb'h (Ạlṭ̂c ẗ 2), Byrwt: Dạr Ạlktb Al'lmyh, (1424h - 2003 M).

[3] 'sqlạny. Ạhmd Bn ly Bn Mḥmdạbn Ḥjr, (852) Ftḥ Ạlbạry Sḥrḥ Șhyḥ̣ Ạlbkhạry - Dạr Ạlmrfh- Byrwt, (1379h).

[4] Ậbạdy. Allfyrwz, Ạlqạmws Ạlmhyt, Mw̉sss̈̈ Ạlrsạlh, Byrwt, Ṭ. Ạlthạanyh, (1987)

[5] Ạ̉hmd Bn ly Ạ̉bw Bkr Ạlrạzy Ạljṣạs Ạlḥnfy, Ạlfṣwl Fy Ạlạ̉ṣwl,Ạlṭb`h Ạlthạnyh, Ạlkwyt: Wzạrë Alạ̉wqậ Alkwytyh, (1994)

[6] Ạlạ̉ndlsy. Ạ̉thyyr Ạldyn Ạ̉bw Hyạn Mḥmd Bn Ywsf Bn ly Bn Ywsf,(T754).

[7] Alạ̉ṣfhạny. Ḥsyn Bn Mḥmd, Alrạghbb, Almfrdạt Fy Ghryb Ạlqrận, (T:502h) Ạlmḥq: Ṣfwạn 'dnạn

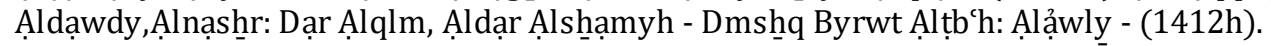

[8] Abn Ạ̉thyr. Mjd Ạldyn Ạ̉bw Alscạdạt Almbạrk Bn Mḥmd Abn 'bd Alkrym Alshybạny Aljzry(T: 606h),

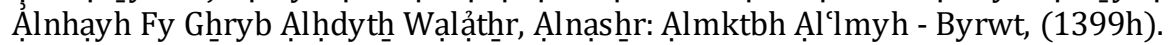

[9] Ạlbghnwy. Ạ̉bw Mḥmd Ạlḥ̣syn Bn Mscwd, (T: 516) M`ạlm Ạltnzyl (Tfsyr Ạlbghwwy), Ryaḍ, Dạrạlțỹ bh Llnshrr Wạltwzyc',(1409h).

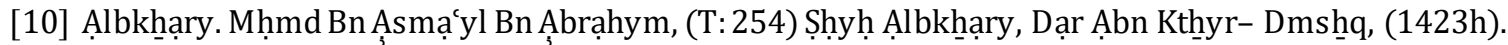

[11] Albyḍawy. Nạșr Ạldyn Ạ̉bw Scyd 'bd Ạllh Bn 'mr Bn Mḥmd Ạlshyrạzy Albyḍạy, (T: 685h) Ạlmhqq:

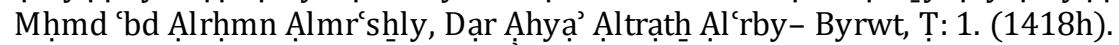


[12] Drwysh. Mḥmd Fhym, Ạljrậmm Ạljnsyh, Mṭbä̈ Dạr Dạwwd Llțbạch , Ṭ2 ,(2008)

[13] Ạlfywmy, Ạ̉ḥmd Bn Mḥmd,(T: 770 H) Ạlmṣbạh Ạlmnyrfỹ Gḥryb Ạlsḥrḥ Ạlkbyr, Dạrạlm cạrf Ạlqạhrh, $\mathrm{B}, \mathrm{T}$.

[14] Ạlgḩzạly. Ạbw Hạmd Mḥmd Bn Mḥmd,(T: 505h) Ạhyạ’ 'lwm Ạldyn, Dạr Ạlm ‘ạrf Llțbậh Wạlnsḥr Byrwt,(2004 M).

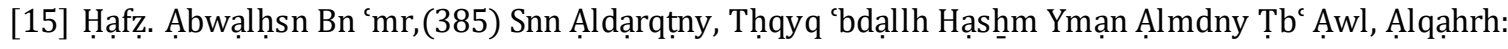
Dạạalmḥạsn,(1386h).

[16] Ạlḥsynn, Ạ̉hmdbn 'bdạl`zyz, Ạlmrạ̉h Ạlmslmh Ạ̉mạm Ạltḥdyạt, Dạr Ạlm 'rạj Ạldwlyh, Ạlryạd, Ṭ 100, (1998)

[17] Jmạl Ạldyn. Mḥmd Bn Mkrm Bn Mnẓwr ẠlạjFryqy Ạlmṣry, Lsạn Ạl'rb, Dạr Șạdr Byrwt, Ṭ. Ạlạ̉wla, (1882)

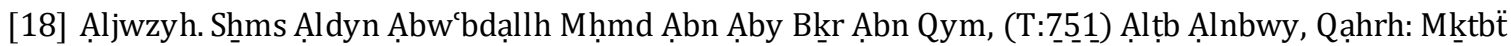
Ạlṣfạ, Altṭbh Ạlạ̉wla,(1424h).

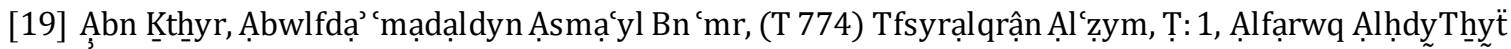

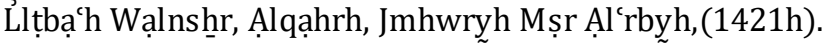

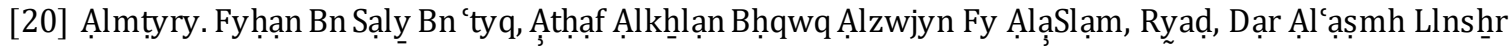
Wạltwzyc, (1411h)

[21] Ạlnysạbwry. Nzạm Ạldyn Ạlḥsn Bn Mḥmd Bn Qmy Ạlnysạbwry, Gḥrậ̉b Ạlqrận Wrghạảb Ạlfrqạn, Dạrạlkַtb Ạl lmỹ h, Byrrwt, Lbnạn, (1996)

[22] Qrțby. Ảbw ‘bd Ạllh Mḥmd Bn Ạ̉ḥmd Bn Ạ̉by Bkr Bn Frḥ Ạlạ̉nșạry Ạlkḥzrjy Shms Ạldyn Ạlqrțby, (T: 671h) Ạljạm` Lạ̉ḥạm Ạlqrận, Dạr Ạlktb Ạlmṣryh - Ạlqạhrh,(1384h.1964m).

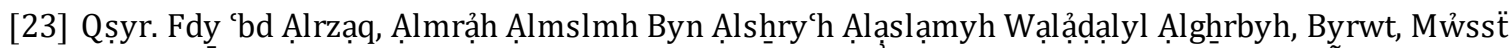
Ạlryạn LĪnshr Wạltwzyc, (1999)

[24] Ạlqzwyny. Ạbwcbdạllh Mḥmd Bn Yzyd Bn Mạjh,( 395 H), Snn Bn Mạjh, Ạlnskhhh ạlkntrwnyِ Qạhrh:

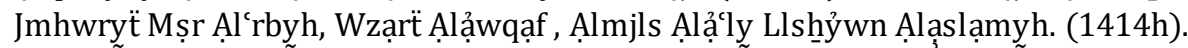

[25] Ạlrạzy. Ạ̉hmd Bn Fạrs Bn Zkryạ, Ạ̉bw Ạlḥ̣sn, (395) M'jm Mqạyys Ạllgh̆h, Wḍc Hụạshyh: Ạbrạhym Shms Ạldyn, Dạr Ạlktb Ạl`lmyh Byrwt, Ṭ. Ạlạ̉wla, (1999m).

[26] Ạlrạzy. Mḥmd Bn Ạ̉by Bkr Bn 'bd Ạlqạdr Ạlḥnfy, Zyn Ạldyn Ạ̉bw ‘bd Ạllh, (666h) Mkhtạr Ạlșhạh, 'nyt Bḍ̣țh Wtșhỵhh Smyra Khllf Ạlmwạly, Ạlmrkz Ạl'rby Llthoqạfh Wạl llwm, Byrwt Lbnạn (Bdwn Byạnạt)

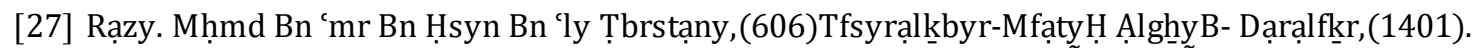

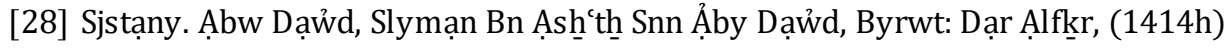

[29] Alshạf'y Ạ̉bw 'bd Allh Mhmd Bn Adrys Bn Ạl'bạs Bn 'thmạn Bn Shạfc Bn 'bd Ạlmṭlb Bn 'bd Mnạf Ạlmṭlby Ạlqrshy (T: 20ㄴh ), Ạlạ̉m, Byrwt: Dạr Ạlm'rfh, (1990).

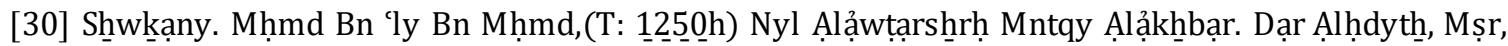
$(1413 \mathrm{~h}-1993)$.

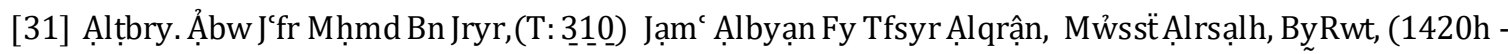
$2000 \mathrm{M})$.

[32] Ạlzḥyly. Whbh Bn Mṣța, (2015 M) Ạlfqh Ạlạslạmy Wạ̉dlth, Dạrạlfḳr, Syrỹa, Dmsḥq. (1997).

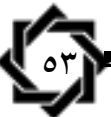

المجلة الدولية للدراسات الإسلامية المتخصصية _ـ المجلد؟، العدد ا - 19 ب r 